\title{
Kinetic Analysis of the Austenite Grain Growth in GCr15 Steel
}

\author{
Chongxiang Yue, Liwen Zhang, Shulun Liao, and Huiju Gao
}

(Submitted June 9, 2008; in revised form February 6, 2009)

\begin{abstract}
The growth behavior of austenite grains in GCr15 steel was investigated through the isothermal annealing tests of the steel under different heating temperatures and holding times. The tests were performed on a Gleeble-3800 thermo-mechanical simulation machine. Austenitizing temperatures 1223, 1323, 1373, and $1423 \mathrm{~K}$ were chosen, and holding time varied from 0 to $480 \mathrm{~s}$. Experimental results suggest that austenite grains grow gradually with the increase of heating temperature, and holding time has an important effect on the growth of austenite grains. The time exponent for the growth is bigger at higher temperature, and the growth rate decreases with increasing time. On the basis of previous models and experimental results, a mathematical model that can describe the growth behavior of austenite grains in the tested steel under different heating temperatures and holding times was obtained using regression analysis. The predicted grain sizes by the model are in good agreement with measured ones.
\end{abstract}

Keywords annealing, austenite grain, GCr15 steel, growth kinetics

\section{Introduction}

Austenite grain growth is an important factor to determine the microstructure because grain size influences the kinetics of phase transformation during the cooling cycle (Ref 1,2$)$. It is well known that the microstructure has a large effect on the mechanical properties of product, so it is important to control grain growth in metals and alloys. Some investigations on the grain growth kinetics for low carbon steel and microalloyed steel have already been reported (Ref 2-4), but few efforts have been expended to understand the grain growth behavior in bearing steel. The objective of this paper is to study the effect of heating temperature and holding time on the growth behavior of austenite grains in GCr15 bearing steel, and obtain a mathematical model which can describe the behavior. The work provides a sound basis for numerical simulation of microstructure evolution during the hot working process of the steel and is useful to optimize the process.

\section{Experimental Procedure}

GCr15 steel employed in the present investigation is provided in the form of bar with the diameter of $15 \mathrm{~mm}$ by Dongbei Special Steel Group, China. The chemical composition

Chongxiang Yue, Liwen Zhang and Shulun Liao, School of Materials Science and Engineering, Dalian University of Technology, Dalian 116085, China; and Huiju Gao, Dongbei Special Steel Group, Dalian 116031, China. Contact e-mail: commat@student.dlut.edu.cn. (wt.\%) of the steel is $0.99 \mathrm{C}, 0.24 \mathrm{Si}, 0.31 \mathrm{Mn}, 0.010 \mathrm{P}, 0.003 \mathrm{~S}$, $1.44 \mathrm{Cr}, 0.05 \mathrm{Ni}, 0.12 \mathrm{Cu}, 0.02 \mathrm{Mo}$, and the balance is Fe. The initial microstructure of the material is lamellar pearlite. Before the experiment, cylindrical samples, with the diameter of $8 \mathrm{~mm}$ and the length of $12 \mathrm{~mm}$, were machined out of the hot-rolled bars with their cylinder axes parallel to the axial line direction of the bar. In order to investigate the growth kinetics of austenite grains in the tested steel, the isothermal annealing tests were performed on a Gleeble-3800 thermo-mechanical simulation machine. The samples were heated to the austenitizing temperature $(1223,1323,1373$, and $1423 \mathrm{~K})$ at the rate of $5 \mathrm{~K} / \mathrm{s}$, and held at the temperature for various times $(0,40$, 120,300 , and $480 \mathrm{~s}$ ) before being quenched in water. After the annealing tests, the quenched samples were polished by conventional metallographic techniques and etched in picric acid at $323-333 \mathrm{~K}$ to reveal austenite grain boundaries. Austenite grain sizes were determined by the mean linear intercept method.

\section{Results and Discussion}

\subsection{Microstructural Characteristics}

Figure 1 shows the typical micrographs of austenite grain boundaries under different heating temperatures and holding times. It can be seen from Fig. 1(a) and (b) that the austenite grains grow gradually when heating temperature increases from 1323 to $1423 \mathrm{~K}$, and the foremost difference between them is that there are less small grains in Fig. 1(b). The decrease of small grains reveals that bigger austenite grains can merge smaller ones and grow gradually with the increase of heating temperature. Figure 1(c) and (d) displays the austenite grain boundaries after holding 120 and $480 \mathrm{~s}$ at $1423 \mathrm{~K}$. The comparison indicates that the growth of austenite grains is remarkable at the tested temperature with the increase of holding time. 


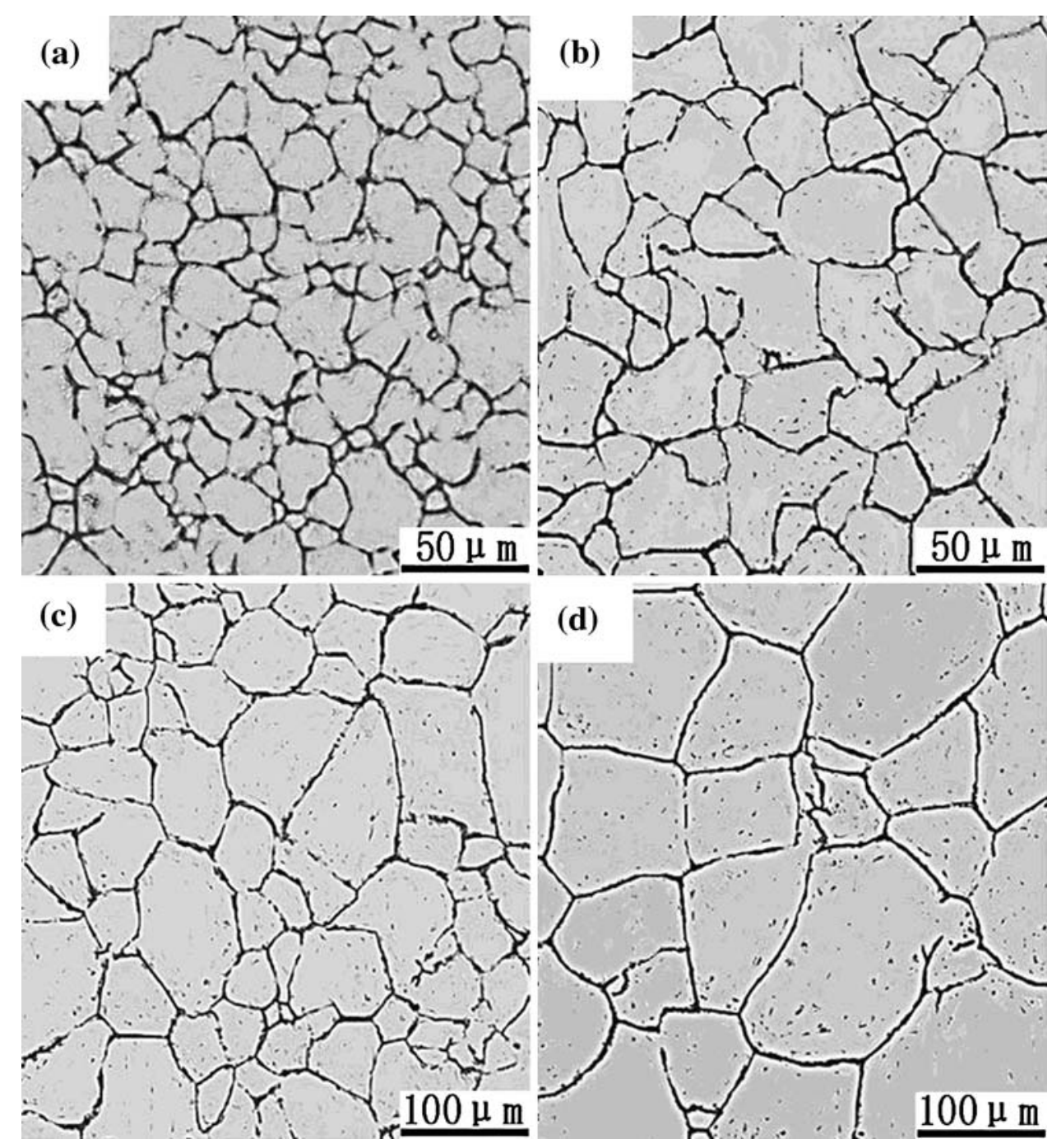

Fig. 1 Micrographs of austenite grain boundaries under different annealing conditions: (a) $1323 \mathrm{~K}$, $0 \mathrm{~s}$; (b) $1423 \mathrm{~K}, 0 \mathrm{~s}$; (c) $1423 \mathrm{~K}$, $120 \mathrm{~s}$; (d) $1423 \mathrm{~K}, 480 \mathrm{~s}$

\subsection{Austenite Grain Growth Kinetics of GCr15 Steel}

Austenite grain growth during the hot working process of metals is an important factor to determine the final microstructure and mechanical properties of product. In order to understand the growth behavior under different conditions, it is necessary to investigate the effect of heating temperature and holding time on the growth kinetics of austenite grains. Figure 2 illustrates the grain sizes as a function of holding time when heating temperatures vary from 1223 to $1423 \mathrm{~K}$. The micrographs of austenite grain boundaries after holding 0 $300 \mathrm{~s}$ at $1223 \mathrm{~K}$ are too unclear to get the average size of these grains, so only three curves are showed in Fig. 2. The curves reveal that the growth behavior of austenite grains at different temperatures is similar. First, in general, the austenite grain size increases and the growth rate decreases with increasing time. Second, for all temperatures, the decrease in the growth rate is initially rapid and then becomes slow over long times. Moreover, it is evident that both the grain sizes and the growth rate are bigger at higher temperatures. The observations are similar to other materials which have been reported (Ref 5-9) under the condition of normal grain growth. As the grains grow in size and the numbers decrease, the grain boundary area diminishes and the total surface energy lowers accordingly. It is generally recognized that the decrease of surface energy as a result of grain growth is the driving force for grain growth. The driving force decreases with the migration of grain boundaries. This is the reason why the grain growth rate decreases with the increase of holding time at each heating temperature. In addition, the migration of grain boundary under the influence of a driving force is a result of atomic displacements from one grain to another across their grain boundary, and can be likened to a diffusion process. So, grain grows at a faster speed with the increase of heating temperature. In some cases, there exists a drag force inhibiting the migration of grain boundary except for the driving force. The drag force can arise due to the pinning effect of second phase particles. So, the presence of second phase particles can reduce the grain growth rate (Ref 2, 10). Some studies (Ref 2) have revealed that the pinning effect decreases with increasing temperature owing to the increase of particles size. To a certain extent, the decrease can promote the growth of austenite grains. 


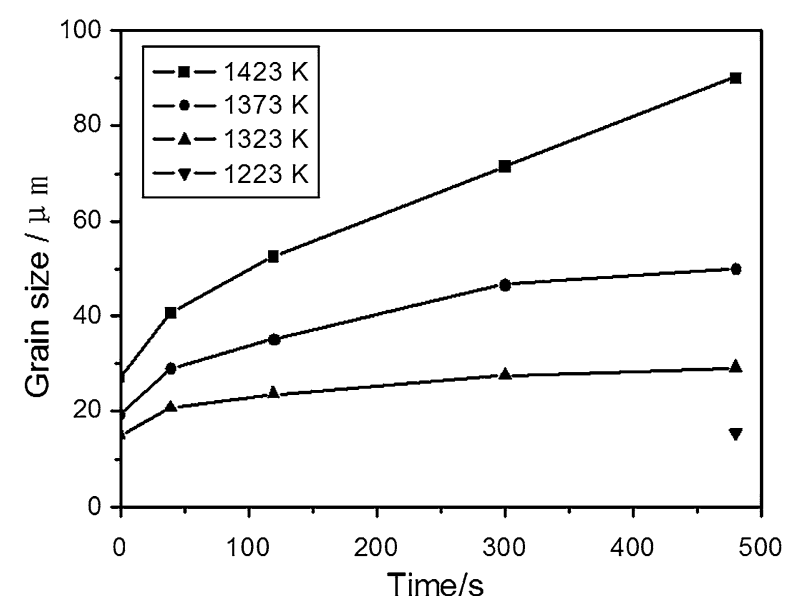

Fig. 2 Austenite grain sizes under different heating temperatures and holding times

Normal grain growth in metals and alloys has frequently been represented by the following empirical equation (Ref 10-12):

$D=k t^{m}$

where $D$ is the average grain size at time $t, t$ is holding time, and $m$ (the time exponent) and $k$ are temperature-dependent parameters.

Equation 1 can reasonably describe the grain growth behavior when $D$ is much greater than the initial grain size $D_{0}$. However, grain growth might have started before reaching the isothermal temperature during the annealing tests. So, the influence of the initial grain size on the growth behavior of grains should be considered, and a general grain growth equation (Ref 13) was developed to substitute Eq 1, which is described as follows:

$D-D_{0}=k t^{m}$

Taking the logarithm of both sides of Eq 2, the following equation can be obtained:

$\ln \left(D-D_{0}\right)=\ln k+m \ln t$

According to the relationship between $\ln \left(D-D_{0}\right)$ and $\ln t$ as shown in Fig. 3, the time exponent $m$ can be determined. The values of $m$ are $0.37,0.48$, and 0.69 at 1323, 1373, and $1423 \mathrm{~K}$, respectively. It is obvious that the time exponent becomes bigger with increasing temperature.

In some papers (Ref 14), Eq 1 was rewritten as:

$D^{n}=K t$

where $n$ (the grain growth exponent) and $K$ are temperaturedependent parameters. The elementary theories of grain growth (Ref 12), which are either based on the proportionality of the growth rate to the interfacial free energy per unit volume or based on the inverse proportionality of the rate of boundary migration to the boundary curvature, predict a value 2 for $n$. However, experimental data (Ref 10, 12, 14) have indicated that in most cases, the value of $n$ is larger than 2, and covers a range from 2 to 5 corresponding to various metallic systems and temperature ranges. For a given metal, it generally decreases with increasing temperature (Ref 12).

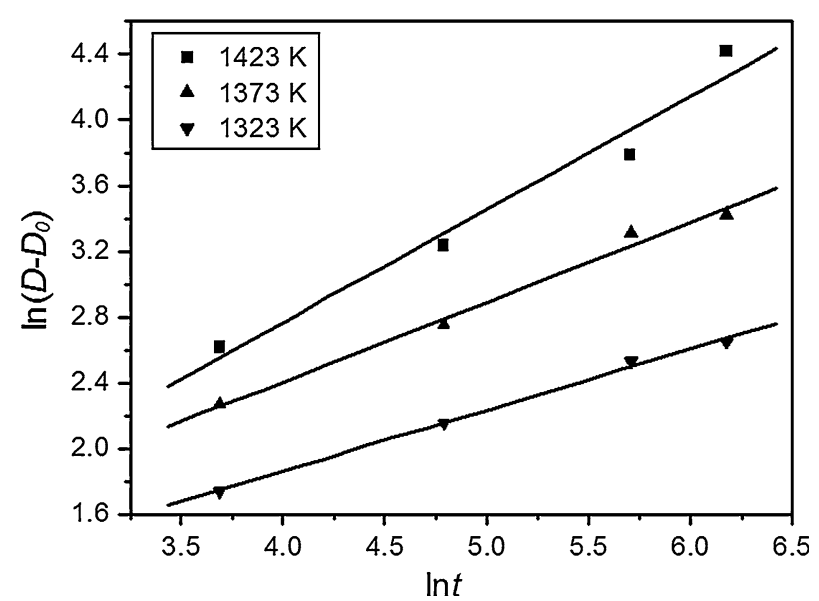

Fig. 3 The relationships between $\ln \left(D-D_{0}\right)$ and $\ln t$ at different temperatures

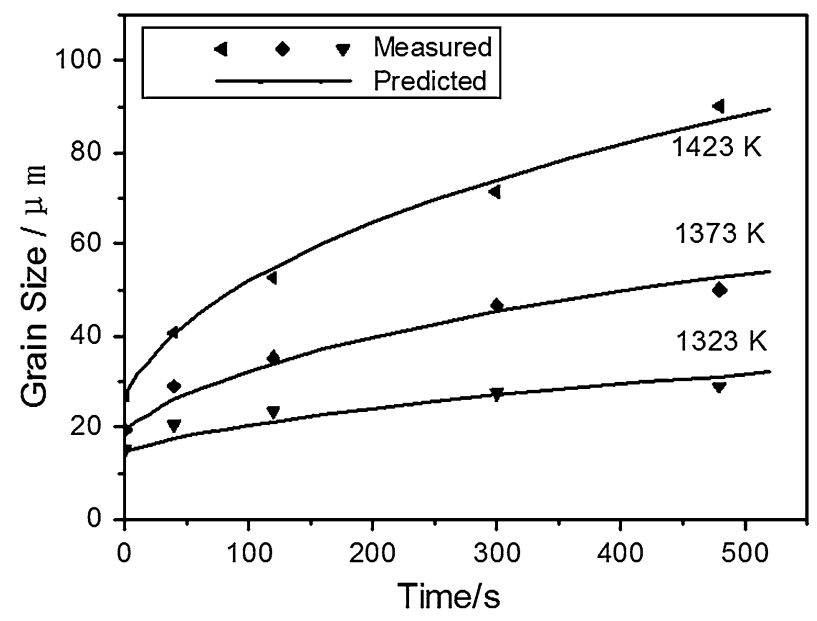

Fig. 4 Comparison of predicted grain sizes by Eq 8 and measured ones

It is a fact that the grain growth exponent $n$ depends on the grain growth mechanism (Ref 13). In a pure system the exponent is 2 , meaning that the system has no defects or precipitates, and the grain growth is controlled by the grain boundary curvature mechanism. For the value of 3 , several phenomena like precipitate phases in the grain are produced. Finally, if the exponent is 4 , it means that there is an effect of the precipitate phases in the grain boundary.

The same as Eq 1, Eq 4 assumes that the initial grain size $D_{0}$ is very small as compared with $D$. When $D_{0}$ is comparable with $D$, a general grain growth equation has been developed to substitute Eq 4, which is described as follows (Ref 10, 12, 15):

$D^{n}-D_{0}^{n}=K t$

The relationship between $K$ and heating temperature, $T$, corresponds to the following Arrhenius formula:

$K=K_{0} \exp (-Q / R T)$

where $Q$ is the activation energy for grain growth, $K_{0}$ is the pre-exponential term, $R$ is the general gas constant, and $T$ is the absolute temperature. 
Equations 5 and 6 can be combined to construct a new equation:

$D^{n}-D_{0}^{n}=K_{0} \exp (-Q / R T) t$

where the effect of heating temperature and holding time on austenite grain size is considered synthetically. Some researchers (Ref 9,10,14,15) have obtained the values of $n$, $K_{0}$, and $Q$ for other metals and alloys using different methods. Results testify that the grain growth equation (Eq 7) can describe the growth behavior of grains under different temperatures and times accurately. In this paper, application software 1stopt was used to perform nonlinear regression analysis of the constants $n, K_{0}$, and $Q$ in Eq 7 on the basis of measured grain sizes. As a result, the optimal values of $n, K_{0}$, and $Q$ were obtained. Then, the grain growth model for the tested steel can be expressed as follows:

$D^{2.77}-D_{0}^{2.77}=3.12 \times 10^{19} \exp \left(-4.58 \times 10^{5} / R T\right) t$

Figure 4 shows a comparison of the grain sizes predicted by Eq 8 and experimental measurements. It is seen that predicted grain sizes are in good agreement with measured ones. The grain growth exponent $n$ is situated between 2 and 3 , indicating that second phase particles in the grain provide a drag force to inhibit the growth of austenite grains.

\section{Conclusion}

The growth behavior of austenite grains in GCr15 steel was investigated by the isothermal annealing tests on a Gleeble3800 thermo-mechanical simulation machine. According to the experimental results, the effect of heating temperature and holding time on the growth behavior was discussed in details, and the following conclusions can be drawn:

(1) The austenite grains of the tested steel grow with the increase of heating temperature and holding time. The growth rate decreases with increasing time and the time exponent for austenite grain growth is bigger at higher temperature.

(2) A model for predicting austenite grain growth under different heating temperatures and holding times is obtained, and predicted results agree well with measured ones.

\section{Acknowledgments}

The authors appreciate the financial support received from Dalian City Government (Liaoning Province, China) and Dongbei Special Steel Group Corporation.

\section{References}

1. W. Li, Z. An, X. Wang, and Y. Rong, Grain Growth Kinetics of Nanocrystalline Martensite in Fe-30 wt.\%Ni Alloy, Mater. Lett., 2008, 62, p 3262-3265 (in English)

2. J. Moon, J. Lee, and C. Lee, Prediction for the Austenite Grain Size in the Presence of Growing Particles in the Weld HAZ of Ti-Microalloyed Steel, Mater. Sci. Eng. A, 2007, 459, p 40-46 (in English)

3. J. Fernández, S. Illescas, and J.M. Guilemany, Effect of Microalloying Elements on the Austenite Grain Growth in a Low Carbon HSLA Steel, Mater. Lett., 2007, 61, p 2389-2392 (in English)

4. J. Wang, J. Chen, Z. Zhao, and X.Y. Ruan, Modeling of Microstructural Evolution in Microalloyed Steel During Hot Forging Process, Acta. Metall. Sin. (Engl. Lett.), 2006, 19(4), p 279-286 (in English)

5. F. Liu, G. Yang, H. Wang, Z. Chen, and Y. Zhou, Nano-Scale Grain Growth Kinetics, Thermochim. Acta, 2006, 443, p 212-216 (in English)

6. B. Zuo and T. Sritharan, Ordering and Grain Growth in Nanocrystalline $\mathrm{Fe}_{75} \mathrm{Si}_{25}$ Alloy, Acta Mater, 2005, 53, p 1233-1239 (in English)

7. F. Ebrahimi and H. Li, Grain Growth in Electrodeposited Nanocrystalline fcc Ni-Fe Alloys, Scr. Mater, 2006, 55, p 263-266 (in English)

8. P. Cao, L. Lu, and M.O. Lai, Grain Growth and Kinetics for Nanocrystalline Magnesium Alloy Produced by Mechanical Alloying, Mater. Res. Bull., 2001, 36, p 981-988 (in English)

9. W.M. Tang, Z.X. Zheng, H.J. Tang, R. Ren, and Y.C. Wu, Structural Evolution and Grain Growth Kinetics of the $\mathrm{Fe}-28 \mathrm{Al}$ Elemental Powder During Mechanical Alloying and Annealing, Intermetallics, 2007, 15, p 1020-1026 (in English)

10. W. Li and K. Xia, Kinetics of the $\alpha$ Grain Growth in a Binary Ti-44Al Alloy and a Ternary Ti-44Al-0.15Gd Alloy, Mater. Sci. Eng. A, 2002, 329/331, p 430-434 (in English)

11. L. Gavard, F. Montheillet, and J. Le Coze, Recrystallization and Grain Growth in High Purity Austenitic Stainless Steels, Scr. Mater., 1998, 39(8), p 1095-1099 (in English)

12. Y. Xun, E.J. Lavernia, and F.A. Mohamed, Grain Growth in Nanocrystalline Zn-22\% Al, Mater. Sci. Eng. A, 2004, 371, p 135140 (in English)

13. S. Illescas, J. Fernández, and J.M. Guilemany, Kinetic Analysis of the Austenitic Grain Growth in HSLA Steel with a Low Carbon Content, Mater. Lett., 2008, 62, p 3478-3480 (in English)

14. R. Rong, W. Yucheng, T. Wenming, W. Fengtao, W. Tugen, and Z. Zhixiang, Synthesis and Grain Growth Kinetics of In Situ FeAl Matrix Nanocomposites (II), Trans. Nonferrous Met. Soc. China, 2008, 18, p 66-71 (in English)

15. K. Farrell and P.R. Munroe, Grain Growth in Fe-30at.\%Al, Scr. Mater., 1996, 35(5), p 615-621 (in English) 